\title{
Anion transport through ceramic electrodialysis membranes made with hydrated cerium dioxide
}

Julia Mora-Gómez ${ }^{\mathrm{a}}$, Montserrat García-Gabaldón ${ }^{\mathrm{a}^{*}}$, Manuel C. Martí-Calatayud ${ }^{\mathrm{a}, \mathrm{b}}$, Sergio Mestre ${ }^{\mathrm{c}}$, Valentín Pérez-Herranz ${ }^{\mathrm{a}}$

${ }^{a}$ IEC Group, Departament d'Enginyeria Quimica i Nuclear, Universitat Politècnica de València, Camí de Vera s/n, 46022, València, P.O. Box 22012, E-46071, Spain

*Corresponding autor: Fax: +34-96-3867639; Tel:+34-96-3877632;

E-mail: mongarga@iqn.upv.es

${ }^{b}$ RWTH Aachen University, Chemical Process Engineering, Forckenbeckstr. 51, 52074, Aachen (Germany)

${ }^{c}$ Instituto Universitario de Tecnología Cerámica/Departamento de Ingeniería Química, Universitat Jaume I. Campus Universitario Riu Sec, Av. Vicent Sos Baynat s/n, 12006, Castellón, Spain

\begin{abstract}
In this research low-cost ceramic anion-exchange membranes have been developed from porous supports manufactured using a chamotte as a pore former. An inorganic anion-exchanger (hydrated cerium dioxide) has been deposited into the support and fixed by thermal treatment. The effects of some process variables (such as the temperature of the thermal treatment or the $\mathrm{pH}$ of the electrolyte) on the properties of the anion-exchange membranes have been investigated. The electrochemical performance of the resulting membranes has been compared to that exhibited by ceramic anion-exchange membranes based on another anion-exchanger (hydrated zirconium dioxide) deposited into alumina-kaolin supports.
\end{abstract}


The temperature of the thermal treatment applied to fix the hydrated cerium dioxide (HCeD) does not affect the structure nor the electrochemical properties of the membranes. The porosity of the supports obtained using chamotte as pore former was lower than that of the alumina-kaolin ones, which led to a lower deposition of hydrated cerium dioxide than that obtained for hydrated zirconium dioxide $(\mathrm{HZrD})$ in aluminakaolin supports. The higher porosity registered for the HZrD-based membrane also implies higher membrane conductivities. The selective transport of anions through the membranes was enhanced by increasing the number of infiltrating steps, as confirmed from current-voltage curves. However, this behavior was only apparent at acidic or neutral $\mathrm{pH}$, thus confirming the amphoteric character of the anion-exchanger.

Comparing the $\gamma$ parameter (equivalents of ion exchanger per gram of deposited oxide), it is concluded that the porosity of the ceramic supports, consequence of their distinct microstructure, is the main parameter responsible for the difference in the ion-exchange capacity obtained for $\mathrm{HZrD}$ and $\mathrm{HCeD}$ membranes. Consequently, the $\mathrm{CeO}_{2}$ particles used in this work are also good candidates to impart ion-exchange properties to microporous ceramic supports.

Keywords: ceramic anion-exchange membranes, hydrated cerium dioxide, chronopotentiometry, ion-exchange capacity. 


\section{Introduction}

Electrodialysis has been demonstrated to be a valuable technology for treating industrial wastewaters, such as those generated in metal finishing or mining activities ${ }^{1-3}$. The presence of separators in electrochemical reactors is crucial when reagents or products taking part in one electrode process are susceptible to react at the counter electrode ${ }^{4}$. Ion-exchange membranes are especial types of membranes, which are capable of separating ions initially present in an electrolyte solution depending on their polarity. The application of electrodialysis membranes in electrochemical reactors is usually limited by the poor chemical resistance of polymers, membrane fouling and concentration polarization. Especially, concentration polarization may lead to a substantial increase of the electrical resistance of the membrane and can cause the precipitation of metallic hydroxides at the membrane surface ${ }^{5-7}$. These facts reduce the applicability of these type of membranes to the treatment of dilute solutions ${ }^{8}$. Therefore, in some applications it is more appropriate to work with membranes made from ceramic materials instead of polymeric ones, as they exhibit better stability in extreme acidic or basic conditions, as well as under the action of oxidizing agents ${ }^{5,8,9}$. Ultimately, the above-mentioned advantages entail long life services and a more feasible application of chemical cleanings to recover the initial membrane performance.

Previous works have emphasized that the use of ceramic membranes with enhanced ion transport properties can be a competitive alternative to polymeric ones for treating specific industrial wastewaters, as they show better chemical resistance and can be obtained with a rather low $\operatorname{cost}^{5,10,11}$. In this sense, hydrated oxides of multivalent metals (such as cerium, barium or zirconium) are potential candidates for manufacturing ceramic ion-exchange membranes. Among them, zirconium has been demonstrated to 
be a good alternative, since hydrated zirconium dioxide is stable in acidic and oxidizing media $^{12}$. Different works have focused on the production of ceramic membranes modified with hydrated zirconium dioxide $(\mathrm{HZrD})^{10,13-15}$, which have shown anionexchange properties. Inorganic membranes modified with zirconium hydrophosphate demonstrated similar behavior regarding cations ${ }^{15-17}$. However, very little work has been conducted regarding the impregnation of ceramic supports with other type of inorganic ion-exchangers. Among them, the application of hydrated cerium dioxide has not been investigated in depth.

The objective of the present paper is to study the electrochemical behavior of new ceramic anion-exchange membranes based on hydrated cerium dioxide (HCeD) and to compare it with that observed for anion-exchange ceramic membranes based on hydrated zirconium dioxide ${ }^{15}$. The new membranes presented in this work combine $\mathrm{HCeD}$ with a low-cost ceramic support that has been designed using a home-made chamotte as pore former. The support was obtained from a mixture of clay, sodium feldspar, feldspatic sand and the chamotte. The use of chamottes instead of organic compounds as pore formers implies a substantial reduction of the duration of the thermal treatment needed to produce microporous ceramics, hence entailing a significant decrease of the manufacturing costs. The morphology, composition and pore size distribution of the resulting membranes manufactured at different thermal treatment temperatures $\left(250\right.$ and $\left.450{ }^{\circ} \mathrm{C}\right)$ were evaluated and their electrochemical performance was also investigated. 


\section{Materials and methods}

\subsection{Synthesis of the membranes}

The chamotte was obtained from a mixture of $10 \%$ of potato starch (Roquette Freres, France) with clay (UA50, Mineraria, Spain), which was dry-blended in a blade mill (Multitrio, Moulinex international, France) and calcined at $1200{ }^{\circ} \mathrm{C}$ with a soaking time of 1 hour. The same clay used in the chamotte synthesis together with micronized sodium feldspar (courtesy of Pamesa, S.A. Spain), feldspatic sand (AFS-125, Imerys, Spain) and the chamotte were proportioned by weight (16/16/8/60 respectively) and dry mixed. The resulting powder was moisturized and dry-pressed, to obtain disks with a diameter of $5 \mathrm{~cm}$ and a thickness of $3 \mathrm{~mm}$. The disks were sintered in an electric furnace at $1100{ }^{\circ} \mathrm{C}$ with a soaking time of 1 hour to obtain the porous supports. The composition of the raw materials used for the synthesis of the membranes is presented in Table 1.

The supports have been functionalized by impregnation with an inorganic anionexchanger, hydrated cerium dioxide. Firstly, the supports were saturated with a $0.5 \mathrm{M}$ aqueous solution of $\left(\mathrm{NH}_{4}\right)_{2} \mathrm{Ce}\left(\mathrm{NO}_{3}\right)_{6} \mathrm{OCl}_{2} \cdot 8 \mathrm{H}_{2} \mathrm{O}$ (98\%, Sigma Aldrich $\mathrm{GmbH}$, Germany). The saturated supports were immersed in a $\mathrm{NH}_{4} \mathrm{OH}(28-30 \%$ wt, Sigma Aldrich GmbH, Germany) solution for $24 \mathrm{~h}$. Afterwards, the supports were rinsed, dried and thermally treated at $250{ }^{\circ} \mathrm{C}$ or $450{ }^{\circ} \mathrm{C}$ to fix the ion exchanger. This procedure was done again up to six times, considering as $\mathrm{n}$ each infiltration cycle. The membranes were weighted after each infiltration cycle and the $\lambda$ parameter was calculated as follows:

$$
\lambda=\frac{\text { mass of hydrated cerium dioxide deposited }}{\text { initial mass of the support }}
$$




\subsection{Chemical and morphological characterization of the membranes}

The equipment employed to measure the pore size distribution and to analyze the mineralogical composition and the morphology of the membranes is well described previously ${ }^{15}$. The distribution of cerium across the membranes was analyzed by Energydispersive X-ray spectroscopy (EDX, Genesis 7000 SUTW, EDAX, USA) connected to a SEM.

\subsection{Electrochemical characterization of the membranes}

\subsubsection{Determination of the ion-exchange capacity}

The ion-exchange capacity (IEC) represents the number of active sites, which are capable of exchanging electrolyte counter-ions, per membrane weight. This value was calculated by equilibrating the membranes successively with $\mathrm{NaOH}$ and $\mathrm{HCl}$ and calculating the amount of $\mathrm{OH}^{-}$ions exchanged by back-titration ${ }^{15}$.

\subsubsection{Chronopotentiometric measurements}

The experimental equipment and the description of the different elements used for the chronopotentiometric measurements is presented in a previous work ${ }^{15}$. The currentvoltage curves of the membranes (or polarization curves) were obtained by plotting the applied current densities (i) against the steady values of the voltage drop of the membrane system $\left(U_{m}\right)$ obtained at the final part of each current pulse.

Electrolytes with different composition were tested to study the behavior of ceramic membranes under different $\mathrm{pH}$ conditions: experiments were carried out at neutral $\mathrm{pH}$ with $\mathrm{NaCl}$ solutions $(\operatorname{Panreac} \AA)$ at different concentrations $(0.01 ; 0.05$; and $0.1 \mathrm{M})$, 
under acidic conditions with a $0.05 \mathrm{M} \mathrm{HCl}$ solution (J.T. Baker ${ }^{\circledR}$ ), and under basic $\mathrm{pH}$ values by using mixtures of $0.05 \mathrm{M} \mathrm{NaCl}$ and $0.05 \mathrm{M} \mathrm{NaOH}$ (J.T. Baker®).

\section{Results and discussion}

\subsection{Membrane characterization}

XRD analysis of the ceramic supports (not shown) confirmed that they were mainly formed by quartz, and contained minor proportions of mullite, albite and potash feldspar. They provide a high chemical resistance to the supports. The proportion of hydrated cerium dioxide deposited in the porous network of the ceramic supports $(\lambda$ parameter), increased linearly with n, as shown in Fig. 1, but was nearly independent of the temperature of the thermal treatment. This result indicates that an increase in the number of infiltration cycles produces a proportional increase in the amount of ion exchanger deposited, and apparently, the degree of hydration of the cerium dioxide is the same for the two temperatures investigated.

As expected from the evolution of $\lambda$ values, the $\mathrm{HCeD}$ infiltration modified the pore size distribution of the supports. Fig. 2 presents the pore-size distribution of the synthesized ceramic anion-exchange membranes as a function of the infiltration cycles and the thermal treatment temperature. From the results depicted it is inferred that the pore size distribution is monomodal for all the membranes under study. The average pore diameter for the unmodified support $(\mathrm{n}=0)$ is about $1.4-1.5 \mu \mathrm{m}$ and the total pore volume $0.177 \mathrm{~cm}^{3} \cdot \mathrm{g}^{-1}$, and these parameters decrease as the number of infiltration cycles increases. This fact confirms that the amount of ion exchanger deposited increases with $\mathrm{n}$ causing a concomitant decrease in the membrane porosity. Moreover, 
the changes in the pore size distribution suggest that the deposited HCeD reduces gradually the diameter of the pores, without blocking them totally. Fig. 2 also shows that the thermal temperature used to fix the anion-exchanger does not cause a substantial effect on the pore size distribution of the synthesized membranes.

Fig. 3 presents the FEG-SEM images obtained for the membrane with $n=6$ together with the EDX analysis for two different areas of the membrane under study: near the surface, Fig. 3 (a), and close to the center part, Fig. 3 (b). A higher magnification of the center section of the membrane, Fig. 3 (c), shows the presence of cerium oxide as whitest areas within the membrane porous structure. It is inferred from Fig. 3, that the HCeD was distributed throughout the whole porous network of the membrane.

\subsection{Electrochemical behavior of the membranes}

\subsubsection{Ion exchange properties}

The evolution of the IEC with $\mathrm{n}$ does not follow the same pattern as $\lambda$, as seen in Fig. 4 , where IEC tends to an asymptotic value as $\mathrm{n}$ is increased. This non-linear increase of IEC may be caused by a decrease in the average pore size (see Fig. 2) with increasing the infiltration cycles. In addition, the formation of agglomerates of hydrated cerium dioxide also increases, thus resulting in a decrease in the ratio: effective area of the support/mass of cerium deposited. Therefore, an optimal relationship between the number of infiltration cycles and porosity is required. Moreover, Figs. 1 and 4 also show that both $\lambda$ and IEC parameters are practically the same for both temperatures under study.

Table 2 presents the values of IEC, open porosity and $\lambda$ obtained for the membranes under study, infiltrated with $\mathrm{HCeD}$, and for the membranes infiltrated with $\mathrm{HZrD}$, 
analysed in a previous work ${ }^{15}$. Comparing the values of $\lambda$ for both types of membranes it is observed that those obtained for $\mathrm{HZrD}$ are considerably higher than those for $\mathrm{HCeD}$ for any value of $n$. This fact may be attributed to the higher porosity of the membranes impregnated by $\mathrm{HZrD}$ particles in comparison to that observed for $\mathrm{HCeD}$. In the case of the $\mathrm{HZrD}$, the ceramic supports were formed by an alumina-kaolin matrix and starch was added as a pore former. On the contrary, in the case of the HCeD, the membranes have been synthesized from a mixture of natural minerals (clays and feldspars), with a porous chamotte as pore generator, giving rise to a more uniform pore size distribution together with lower values of porosity. In consequence, the volume of pores that can be filled with the cerium nitrate solution was lower, which reduces the maximum quantity of $\mathrm{HCeD}$ that could be deposited. The higher value of $\lambda$ obtained for the HZrD leads to higher ion exchange capacities. In spite of this fact, the values of IEC reported for the $\mathrm{HCeD}$ membranes are similar to those obtained for other ceramic anion-conducting membranes ${ }^{19}$ or even higher ${ }^{20-22}$.

In order to compare the ion-exchange properties of both inorganic ion-exchangers, $\mathrm{HZrD}$ and $\mathrm{HCeD}$, the ratio of $\lambda$ and IEC for both membranes is plotted in Fig. 5, where it is observed that $\lambda$ for $\mathrm{HZrD}$ is about 1.5 times that of HCeD, and consequently, the ratio between the IEC value obtained for each membrane is close to this value, except for $\mathrm{n}=6$, where the IEC ratio is higher (about 2). This result could be explained in terms of the different dependency between pore size distribution and $\mathrm{n}$ obtained for both types of ion exchanger. In the case of the anion-exchange membranes infiltrated with $\mathrm{HZrD}^{15}$, the effect of the starch addition on the ceramic supports led to a trimodal pore structure for $\mathrm{n}=0,2$ and 4 , whereas the membranes with $\mathrm{n}=6$ only showed two characteristic pore diameters. This change of structure was caused by the progressive 
insertion of ion exchanger inside the larger pores. Hence, it was concluded that $\mathrm{ZrO}_{2}$ deposits preferently over previously infiltrated $\mathrm{ZrO}_{2}$ particles.

As mentioned previously, because of the difference in porosity, the amount of material deposited $(\lambda)$ is very different and this fact affects the ion-exchange capacity (IEC) of the membranes. In an attempt to evaluate only the contribution of the ion exchanger to the IEC values, a new parameter $(\gamma)$ has been calculated: equivalents of ion exchanger per gram of deposited oxide; which is plotted in Fig. 6 for both types of membranes. According to the data presented in Fig. 6, the equivalents of ions that can be exchanged per gram of oxide deposited is similar for both types of anion-exchangers. Hence, the different behavior observed in terms of IEC and $\lambda$ was due to the differences of porosity and microstructure of the ceramic supports rather than to the difference in the ionexchange capacity of the HZrD and the HCeD.

\subsubsection{Chronopotentiometric response}

The chronopotentiometric response obtained for the $\mathrm{CeO}_{2}$-infiltrated membranes is shown in Figs. 7 and 8. In the present section, only the behavior of the membranes obtained with a thermal treatment at $250^{\circ} \mathrm{C}$ will be discussed, since no significant effect of the thermal treatment temperature on the membrane performance was found. The influence of the number of impregnation cycles on the chronopotentiometric response is represented in Fig. 7. The results obtained for the unmodified porous supports show a flat evolution of $U_{m}$ with time for all applied current pulses (see Fig. 7(a)). Hence, it is proven that the raw porous supports do not exhibit any selectivity for anions or cations so that concentration polarization effects are not remarkable. In contrast, the curves obtained for membranes with more infiltration cycles (Fig. 7(b)-(d)) are analogous to 
those observed for electrodialysis membranes ${ }^{23-25}$. The ohmic overpotential is registered directly after switching on the current. When higher currents are applied, the membrane voltage drop increases more importantly during the pulse. This behavior is the conventional one observed when using membranes with enhanced ion transport properties and is related to the development of concentration profiles at the membrane/solution interfaces. When the concentration of counterions, in the present case anions, decreases to values close to zero at the depleting membrane surface, the electrical resistance of the membrane system grows, which is reflected in the curves by an acute increase of $U_{m}$. The difference between the final value of $U_{m}$ registered at the end of the current pulse and the ohmic overpotential is known as the interfacial transfer overvoltage. This parameter is related to the ion-exchange properties provided by hydrated cerium oxide, which involves an increased transfer of anions through the membranes ${ }^{26}$. As observed, the higher the applied current is, the greater the value of the interfacial transfer overvoltage is, since the reduction of the counter ion concentration $\left(\mathrm{Cl}^{-}\right)$next to the membrane in the depleting compartment is greater.

The initial concentration and $\mathrm{pH}$ of the solutions were also altered in order to investigate the membrane performance in a wide range of conditions. The curves obtained for the membrane with $n=6$ in a variety of solutions is presented in Fig. 8 . This membrane shows the classical behavior of electrodialysis membranes for the three concentrations of $\mathrm{NaCl}$. Comparing the results of Fig. 7 (d) and Figs. 8 (a) and (b), it is inferred that for similar values of applied current, $U_{m}$ decreases as the concentration of $\mathrm{NaCl}$ increases. This is mainly caused by an increase in the electrical conductivity of the system for higher concentrations. An analogous response was also observed when $\mathrm{HCl}$ solutions were tested (Fig. 8(c)), thus confirming that this kind of anion-exchanger is active under acidic conditions. On the contrary, as $\mathrm{NaOH}$ was added to the electrolyte 
(Fig. 8(d)), the chronopotentiograms become similar to those observed for the unmodified supports (Fig. 7(a)). This trend indicates that the membranes are not selective under basic conditions, which agrees with preceding studies carried out with $\mathrm{ZrO}_{2}$ particles $^{10,27}$, and confirm the amphoteric behavior of HCeD.

Regarding the other temperature under study $\left(450^{\circ} \mathrm{C}\right)$, similar results than those previously explained were obtained: the curves of the unmodified ceramic support is practically flat for all applied currents and those of the infiltrated membranes exhibit a substantial variation of $U_{m}$ during the application of the current pulses. The effect of $n$, the electrolyte concentration and $\mathrm{pH}$ on the chronopotentiometric measurements also led to similar conclusions, therefore, these results are not shown in the present publication for the sake of conciseness.

If the previous chronopotentiometric results are compared with those for the membranes infiltrated with $\mathrm{ZrO}_{2}$ particles ${ }^{15}$, it is firstly concluded that the unmodified ceramic support of the present paper involves higher $U_{m}$ values for the same applied currents, since as mentioned previously the porosity of these ceramic supports is considerable lower. This lower porosity leads to a decrease in the amount of $\mathrm{CeO}_{2}$ particles deposited $(\lambda)$ and, consequently, to lower values of IEC.

\subsubsection{Current-voltage curves}

Current-voltage curves represent the relationship between $\mathrm{i}$ and $\mathrm{U}_{\mathrm{m}}$. They are convenient for studying transport phenomena through ion-exchange membranes, since they can be used to obtain relevant characteristic values, such as the limiting current or the resistance of the membrane system. Current-voltage curves reflect the electric 
properties of the membrane and give information about the transport mechanism of ions, including concentration polarization ${ }^{28-32}$.

Fig. 9 shows the current-voltage curves obtained for $0.01 \mathrm{M} \mathrm{NaCl}$ with membranes obtained after a thermal treatment at $450{ }^{\circ} \mathrm{C}$ and varying infiltration steps. A linear trend was observed for the uncharged ceramic support for the range of current densities tested. This behavior indicates the absence of diffusive limitations due to the lacking anion selectivity of the membranes. However, the curves corresponding to the infiltrated supports change their behavior as the current density is increased. At low current densities, the current and the potential drop of the membrane correlate with a quasiohmic behavior. In this region, ions are transferred through the membrane by diffusion and migration. However, when current densities approach the limiting current density, the resistance of the membrane system increases and the curves form a flat area known as "plateau", which is directly associated with the intensification of concentration polarization. This phenomenon becomes apparent with ion-selective membranes, since the rejection of co-ions in the concentrate side together with the enhanced transport of counter-ions originates concentration gradients near the membrane. In the "plateau" region, the concentration of counter-ions on the surface of the membrane approaches zero and the transport of ions is limited by diffusion. In this case, the limiting current density $\left(\mathrm{i}_{\text {lim }}\right)$ is determined by the intersection of the two straight lines corresponding to the ohmic and the "plateau" regions, as shown in Fig. 9.

Fig. 10 represents the current-voltage curves obtained for $0.05 \mathrm{M} \mathrm{NaCl}$ as a function of $\mathrm{n}$ for a temperature of $250^{\circ} \mathrm{C}$. As observed, the membrane with $\mathrm{n}=2$ does not present a "plateau" region and the curves of the support and this membrane are almost superposed. This fact indicates that the IEC achieved after two infiltration cycles is not 
high enough to provide significant anion-selective properties in the case of higher electrolyte concentration.

The shape of the current-voltage curves obtained for acidic pHs (not shown) is very similar to that observed previously in Figs. 9 and 10. On the contrary, in the case of basic $\mathrm{pH}$ the curves (not shown) reflected a quasy-ohmic response over all range of currents applied, which is characteristic of non-selective membranes. These results corroborate the conclusions extracted from the chronopotentiograms.

When a separator is used in an electrochemical reactor, it should be as thin as possible in order to minimize the electrical resistance of the membrane/electrolyte systems, $R_{m}$, whilst retaining structural stability. In the case of a microporous ceramic membrane, the potential difference across the membrane will depend on the thickness of the material and the electrolyte composition. $\mathrm{R}_{\mathrm{m}}$, can be calculated from the inverse of the slopes of the quasi-ohmic region and is used to obtain the effective electrical conductivity of the membranes, $\kappa_{\mathrm{m}}$, as predicts Eq. (2), where e represents the thickness of the membrane:

$$
k_{m}=\frac{\mathrm{e}}{\mathrm{R}_{\mathrm{m}}}
$$

Both, $\kappa_{\mathrm{m}}$ and $\mathrm{i}_{\lim }$ parameters extracted from the current-voltage curves are presented in Table 3 for each membrane/electrolyte and temperature under study. With independency of the temperature applied during the thermal treatment, for a given electrolyte composition, the $\kappa_{\mathrm{m}}$ values decrease when $\mathrm{n}$ is increased. This trend can be explained by the gradual decrease of the membrane pore diameter occurring as the amount of $\mathrm{CeO}_{2}$ particles deposited in the microporous structures increases (see Fig. 1). Consequently, a compromise between the membrane anion selectivity (given by IEC) 
and the membrane conductivity (given by $\kappa_{\mathrm{m}}$ ) is desired. On the other hand, an increase in the ion concentration leads to a higher conductivity in the diffusion boundary layers and inside the microporous membrane, which is reflected by an increase in $\kappa_{\mathrm{m}}$. Since the co-ion also affects the conductivity of the diffusion boundary layers, the higher conductivity of $\mathrm{H}^{+}$ions compared to that of $\mathrm{Na}^{+}$ions causes these greater values of $\kappa_{\mathrm{m}}$ obtained for the $0.05 \mathrm{M} \mathrm{HCl}$ electrolyte related to that of $0.05 \mathrm{M} \mathrm{NaCl}$. Comparing the electrochemical parameters presented in Table 3 with those obtained with $\mathrm{HZrD}^{15}$, it is inferred that the values of $\kappa_{\mathrm{m}}$ are always higher for the latter since the porosity obtained in this case is considerably higher (between 45 and 54\%) than that of HCeD (ranges from 28 to $31 \%$ ), as shown in Table 2 .

As observed in Table 3 , the limiting current value, $\mathrm{i}_{\text {lim }}$, diminishes as $\mathrm{n}$ increases for both temperatures under study. The membranes having increasing amounts of $\mathrm{CeO}_{2}$ particles (n) possess an enhanced selectivity (higher IEC values). As the membrane selectivity is increased, the preferential transport of counterions is promoted and, consequently, the limiting conditions in these membranes are reached at lower values of current density. Moreover, the higher the electrolyte concentration, the higher the limiting current, because higher applied currents are necessary to achieve the depletion of ions in the diluting diffusion boundary layer. 


\section{Conclusions}

A new low-cost ceramic support has been designed using a chamotte as pore former. The use of chamottes implies a reduction of the long thermal cycles that are usually required to oxidize organic pore formers and a concomitant decrease in the manufacturing costs. These supports have been functionalized by infiltrating an inorganic anion-exchanger (hydrated cerium dioxide) to expand the scope of ceramic membranes used in wastewater treatment, especially in those cases where the reactivity of the contaminants impedes the use of polymeric membranes. The effects of some process variables (such as the temperature of the thermal treatment or the electrolyte composition) on the electrochemical properties of the resulting anion-exchange membranes have been investigated. The behavior of the synthesized membranes has also been compared to that exhibited by membranes obtained using another anionexchanger (hydrated zirconium dioxide).

Comparing the values of $\lambda$ (mass of hydrated cerium dioxide deposited related to the mass of the support) for both types of membranes it is inferred than those obtained for the hydrated zirconium dioxide $(\mathrm{HZrD})$ were considerably higher than those for the hydrated cerium dioxide (HCeD). This fact is attributed to the higher porosity of the membranes obtained using starch as pore former in comparison to that observed for those made with chamottes. The higher value of $\lambda$ obtained for the hydrated zirconium dioxide led to higher ion exchange capacities. However, from the evaluation of the $\gamma$ parameter (equivalents of ion exchanger per gram of deposited oxide) it is concluded that the different behavior observed in terms of IEC and $\lambda$ was due to the different porosity of the ceramic supports, consequence of their distinct microstructure, rather 
than to the difference in the ion-exchange capacity of the $\mathrm{HZrD}$ and the $\mathrm{HCeD}$, since both ion-exchangers present similar values. Hence, the $\mathrm{CeO}_{2}$ particles presented in this work are also good candidates to impart ion-exchange properties to microporous ceramic supports.

Our further studies will focus on the development of ceramic supports using chamottes as pore formers, but trying to achieve higher porosities. This would lead not only to lower manufacturing costs, but also to lower energetic costs, as higher porosities imply lower electrical resistance of the membrane/electrolyte systems.

\section{Acknowledgements}

This work was financially supported by the Ministerio de Economía y Competitividad (Spain) with the project number CTQ2012-3750-C02-01/PPQ and CTQ2012-3750-C0202/PPQ. 


\section{References}

${ }^{1}$ M. C. Martí-Calatayud, D. C. Buzzi, M. García-Gabaldón, E. Ortega, A. M. Bernardes, et al., "Sulfuric acid recovery from acid mine drainage by means of electrodialysis," Desalination, 343 120-7 (2014).

${ }^{2}$ J. M. Ortiz, J. A. Sotoca, E. Expósito, F. Gallud, V. García-García, et al., "Brackish water desalination by electrodialysis: Batch recirculation operation modeling,” J. Memb. Sci., 252 65-75 (2005).

${ }^{3}$ K. L. Huang, T. M. Holsen and J. R. Selman, "Impurity diffusion through Nafion and ceramic separators used for electrolytic purification of spent chromium plating solutions," J. Membr. Sci., 221 135-46 (2003).

${ }^{4}$ H. Sharifian and D. W. Kirk, "Electrochemical oxidation of phenol," J. Electrochem. Soc., 133 921-4 (1986).

${ }^{5}$ V. Linkov and V. N. Belyakov, "Novel ceramic membranes for electrodialysis," Sep. Purif. Technol., 25 57-63 (2001).

${ }^{6} \mathrm{~T}$. Okada, "Theory for water management in membranes for polymer electrolyte fuel cells. Part 1. The effect of impurity ions at the anode side on the membrane performances," J. Electroanal. Chem. 465 1-17 (1999).

${ }^{7} \mathrm{~T}$. Okada, "Theory for water management in membranes for polymer electrolyte fuel cells. Part 2. The effect of impurity ions at the cathode side on the membrane performances,” J. Electroanal. Chem. 465 18-29 (1999).

${ }^{8}$ S. L. Guddati, T. M. Holsen, C. C. Li, J. R. Selman and N. V. Mandich, "The use of a porous ceramic diaphragm for the removal of metallic impurities from chromium plating baths," J. Appl. Electrochem. 29 1129-32 (1999).

${ }^{9}$ G. R. Gallaher and P. K. T. Liu, "Characterization of ceramic membranes I. 
Thermal and hydrothermal stabilities of commercial $40 \AA$ membranes," J. Memb. Sci. 92 29-44 (1994).

${ }^{10}$ Y. S. Dzyazko, A. Mahmoud, F. Lapicque and V. N. Belyakov, "Cr(VI) transport through ceramic ion-exchange membranes for treatment of industrial wastewaters," J. Appl. Electrochem. 37 209-17 (2007).

${ }^{11}$ Y. Sui, X. Fu, R. Zeng and X. Ma, "Preparation, characterization and application of a new type of ion exchanger and solid acid zirconium sulfonated oligopolystyrenylphosphonate-phosphate supported on $\mathrm{ZrO}_{2}$," J. Mol. Catal. A-Chem. 217 $133-8$ (2004).

${ }^{12}$ L. A. Rodrigues, L. J. Maschio, R. E. da Silva and M. L. C. P. da Silva, “Adsorption of $\mathrm{Cr}(\mathrm{VI})$ from aqueous solution by hydrous zirconium oxide," J. Hazard. Mater. 173 630-6 (2010).

${ }^{13}$ Y. S. Dzyazko, A. S. Rudenko, Y. M. Yukhin, A. V. Palchik and V. N. Belyakov, "Modification of ceramic membranes with inorganic sorbents. Application to electrodialytic recovery of $\mathrm{Cr}(\mathrm{VI})$ anions from multicomponent solution," Desalination. $34252-60$ (2014).

${ }^{14}$ Y. S. Dzyazko, S. L. Vasilyuk, L. M. Rozhdestvenskaya, V. N. Belyakov, N. V. Stefanyak, et al., "Electro-deionization of $\mathrm{Cr}$ (VI)-containing solution. Part II: Chromium transport through inorganic ion-exchanger and composite ceramic membrane," Chem. Eng. Commun. 196 22-38 (2008).

${ }^{15}$ M. C. Martí-Calatayud, M. García-Gabaldón, V. Pérez-Herranz, S. Sales and S. Mestre, "Ceramic anion-exchange membranes based on microporous supports in filtrated with hydrated zirconium dioxide," RSC Adv. 5 46348-58 (2015).

${ }^{16}$ M. C. Martí-Calatayud, M. García-Gabaldón, V. Pérez-Herranz, S. Sales and S. Mestre, "Synthesis and electrochemical behavior of ceramic cation-exchange 
membranes based on zirconium phosphate," Ceram. Int. 39 4045-54 (2013).

${ }^{17}$ S. Singh, P. Patel, V. K. Shahi and U. Chudasama, " $\mathrm{Pb}^{2+}$ selective and highly cross-linked zirconium phosphonate membrane by sol-gel in aqueous media for electrochemical applications," Desalination. 276 175-83 (2011).

${ }^{18}$ B. P. Tripathi and V. K. Shahi, "SPEEK-zirconium hydrogen phosphate composite membranes with low methanol permeability prepared by electro-migration and in situ precipitation," J. Colloid Interface Sci. 316 612-21 (2007).

${ }^{19}$ Y. S. Dzyazko, V. M. Linkov and V. N. Belyakov, "Transport of sulfate anions through inorganic membranes modified by ion-exchange material," Russ. J. Electrochem. 45 1333-9 (2009).

${ }^{20}$ M. Kogure, H. Ohya, R. Paterson, M. Hosaka, J. J. Kim, et al. "Properties of new inorganic membranes prepared by metal alkoxide methods. Part II : New inorganicorganic anion-exchange membranes prepared by the modified metal alkoxide methods with silane coupling agents," J. Membr. Sci. 126 161-9 (1997).

${ }^{21}$ H. Ohya, K. Masaoka, M. Aihara and Y. Negishi, "Properties of new inorganic membranes prepared by metal alkoxide methods. Part III : New inorganic lithium permselective ion exchange membrane," J. Membr. Sci. 146 9-13 (1998).

${ }^{22} \mathrm{C}$. $\mathrm{Wu}, \mathrm{T} . \mathrm{Xu}$ and $\mathrm{W}$. Yang, "A new inorganic-organic negatively charged membrane: membrane preparation and characterizations," J. Membr. Sci. 224 117-25 (2003).

${ }^{23}$ M. C. Martí-Calatayud, M. García-Gabaldón, V. Pérez-Herranz and E. Ortega, "Determination of transport properties of $\mathrm{Ni}(\mathrm{II})$ through a Nafion cation-exchange membrane in chromic acid solutions," J. Memb. Sci. 379 449-58 (2011).

${ }^{24}$ P. Długołecki, B. Anet, S. J. Metz, K. Nijmeijer and M. Wessling, “Transport limitations in ion exchange membranes at low salt concentrations," J. Memb. Sci. 346 
163-71 (2010).

${ }^{25}$ J. Balster, M. H. Yildirim, D. F. Stamatialis, R. Ibanez, R. G. H. Lammertink, et al., "Morphology and microtopology of cation-exchange polymers and the origin of the overlimiting current," J. Phys. Chem. B. 111 2152-65 (2007).

${ }^{26}$ M. Taky, G. Pourcelly, F. Lebon and C. Gavach, "Polarization phenomena at the interfaces between an electrolyte solution and an ion exchange membrane. Part I. Ion transfer with a cation exchange membrane," J. Electroanal. Chem. 336 171-94 (1992).

${ }^{27}$ A. Clearfield, "Role of ion exchange in solid-state chemistry," Chem. Rev. 88 125-48 (1988).

${ }^{28}$ V. M. Barragán and C. Ruiz Bauzá, "Current-Voltage Curves for a CationExchange Membrane in Methanol-Water Electrolyte Solutions," J. Colloid Interface Sci. 247 138-48 (2002).

${ }^{29} \mathrm{Y}$. Tanaka, "Concentration polarization in ion-exchange membrane electrodialysis-the events arising in an arising in a flowing solution in a desalting cell," J. Memb. Sci. 216 149-64 (2003).

${ }^{30}$ V. Shapiro, V. Freger, C. Linder and Y. Oren, “Transport properties of highly ordered heterogeneous ion-exchange membranes," J. Phys. Chem. B. 112 9389-99 (2008).

${ }^{31}$ J. H. Choi, H. J. Lee and S. H. Moon, "Effects of Electrolytes on the Transport Phenomena in a Cation-Exchange Membrane," J. Colloid Interface Sci. 238 188-95 (2001).

${ }^{32}$ M. Kumar, B. P. Tripathi and V. K. Shahi, "Ionic transport phenomenon across sol-gel derived organic-inorganic composite mono-valent cation selective membranes," J. Memb. Sci. 340 52-61 (2009). 


\section{List of Figures}

Fig. 1. Effect of the number of infiltration cycles with hydrated $\mathrm{CeO}_{2}$ particles (n) on $\lambda$. Fig. 2. Pore size distribution as a function of the number of infiltration cycles with $\mathrm{HCeD}(\mathrm{n})$ and the temperature of the thermal treatment.

Fig 3. SEM image and EDX analysis of polished sections of the membrane obtained with 6 infiltration cycles and $250^{\circ} \mathrm{C}$ : (a) Surface of the membrane, (b) central section and (c) magnification of central section of the membrane (the whitest areas correspond to the cerium hydrated oxide).

Fig. 4. Effect of the number of infiltration cycles with hydrated $\mathrm{CeO}_{2}$ (n) on IEC.

Fig. 5. Effect of the number of infiltration cycles on the ratio of $\lambda$ and IEC expressed as $\mathrm{HZrD} / \mathrm{HCeD}$.

Fig. 6. Ion-exchange capacity per gram of material deposited

Fig. 7. Chronopotentiometric response obtained for $0.01 \mathrm{M} \mathrm{NaCl}$ with (a) the microporous support without $\mathrm{CeO}_{2}(\mathrm{n}=0)$, and the membranes infiltrated with $\mathrm{HCeD}$ : (b) $n=2$, (c) $n=4$, and (d) $n=6$.

Fig. 8. Chronopotentiometric response obtained for the membrane obtained after 6 infiltration cycles with different electrolyte solutions: (a) $0.05 \mathrm{M} \mathrm{NaCl}$, (b) $0.1 \mathrm{M} \mathrm{NaCl}$, (c) $0.05 \mathrm{M} \mathrm{HCl}$ and (d) mixtures of $0.05 \mathrm{M} \mathrm{NaCl}$ and $0.05 \mathrm{M} \mathrm{NaOH}$.

Fig. 9. Current-voltage curves obtained for $0.01 \mathrm{M} \mathrm{NaCl}$ solutions and varying number of infiltration steps. The thermal treatment applied to fix the anion-exchanger was conducted at $\mathrm{T}=450^{\circ} \mathrm{C}$.

Fig. 10. Current-voltage curves obtained for $0.05 \mathrm{M} \mathrm{NaCl}$ solutions and varying number of infiltration steps. The thermal treatment applied to fix the anion-exchanger was conducted at $\mathrm{T}=250^{\circ} \mathrm{C}$. 


\section{List of Tables}

Table 1. Chemical composition of inorganic raw materials (wt $\%)$.

Table 2. Values of IEC, open porosity, and $\lambda$ for both $\mathrm{HZrD}$ and $\mathrm{HCeO}$ as a function of the number of infiltration cycles.

Table 3. Values of the electrochemical parameters as a function of the number of infiltration cycles and temperature. 


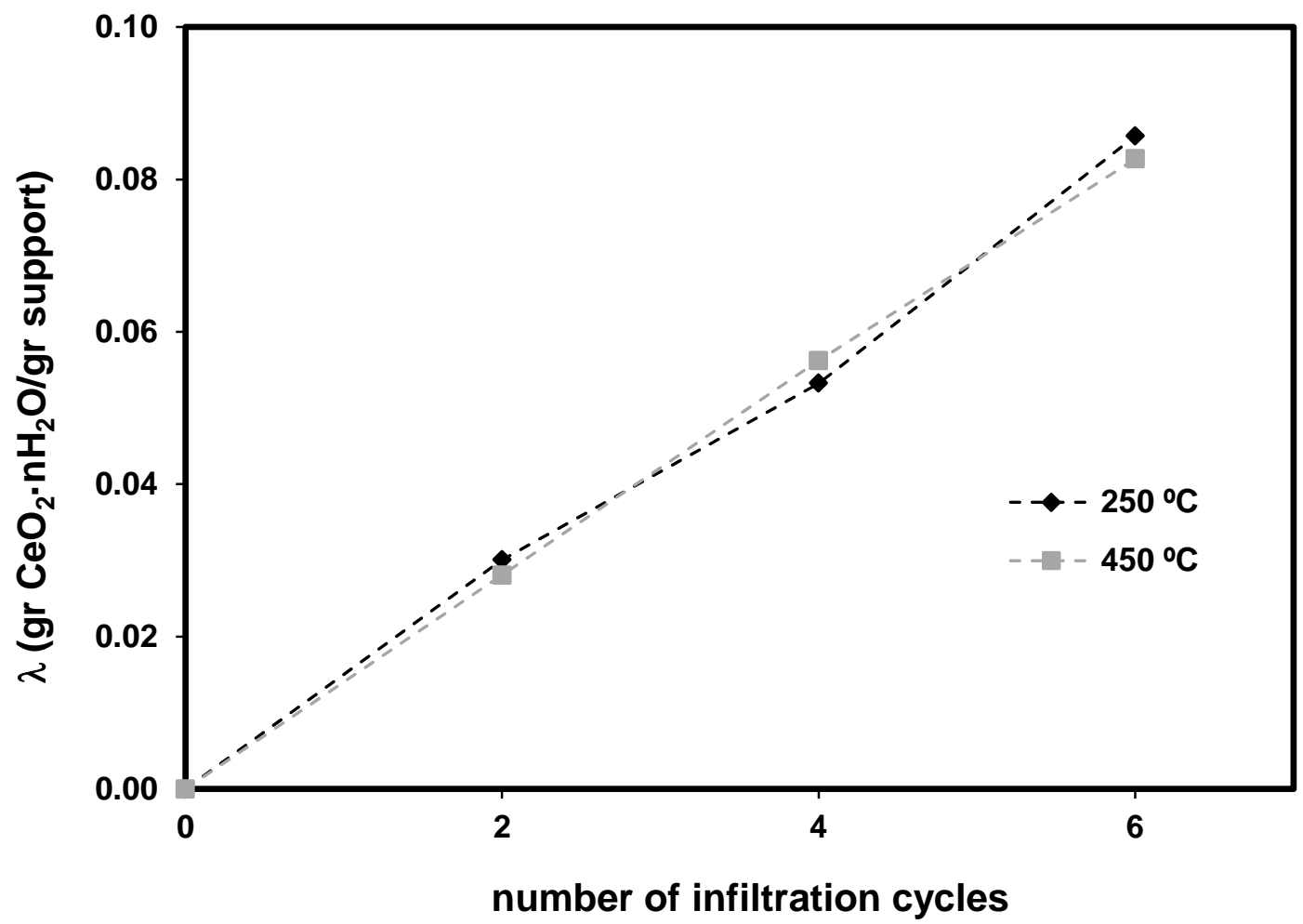

Fig. 1. Effect of the number of infiltration cycles with hydrated $\mathrm{CeO}_{2}$ particles (n) on $\lambda$. 


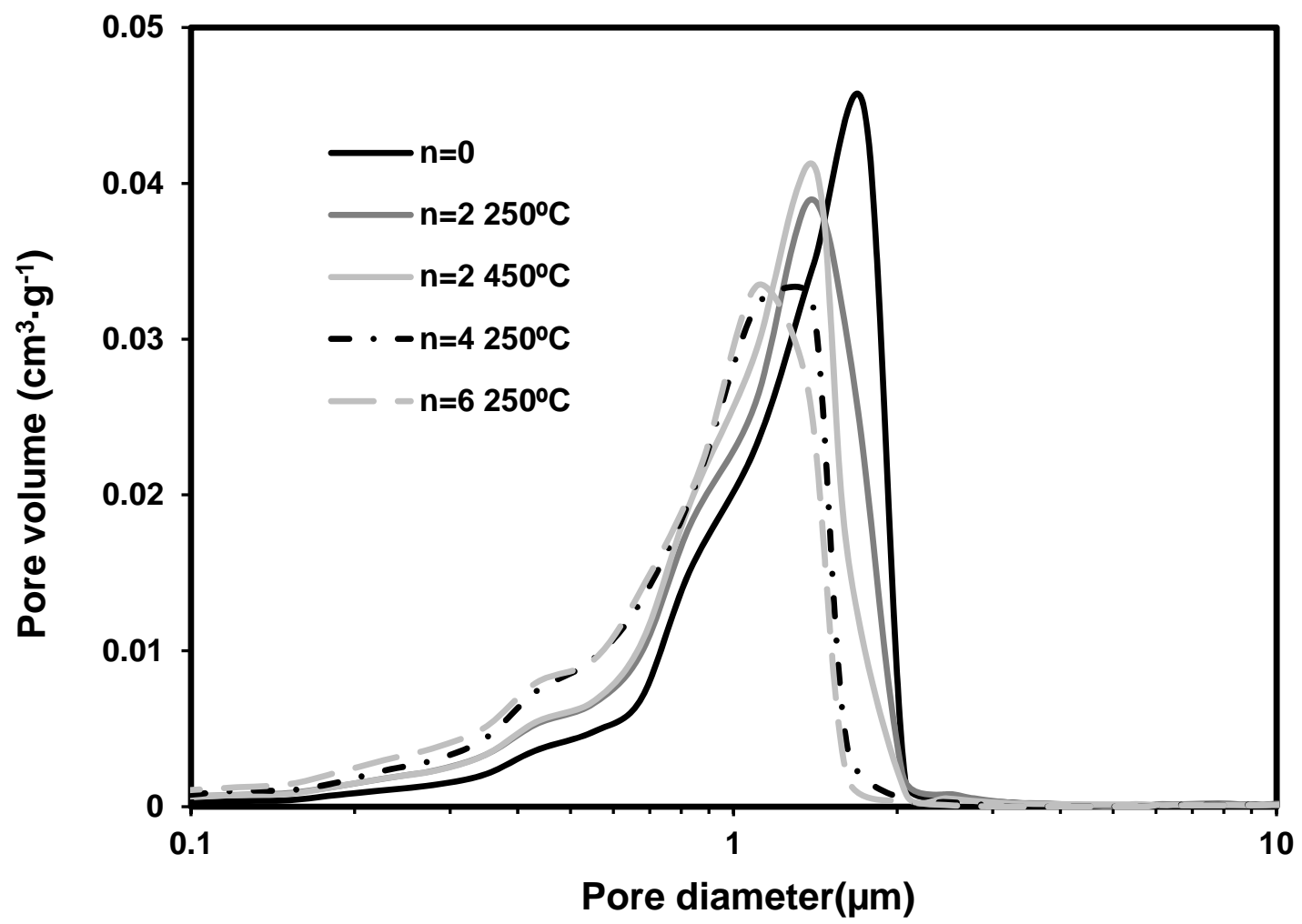

Fig. 2. Pore size distribution as a function of the number of infiltration cycles with $\mathrm{HCeD}(\mathrm{n})$ and the temperature of the thermal treatment. 


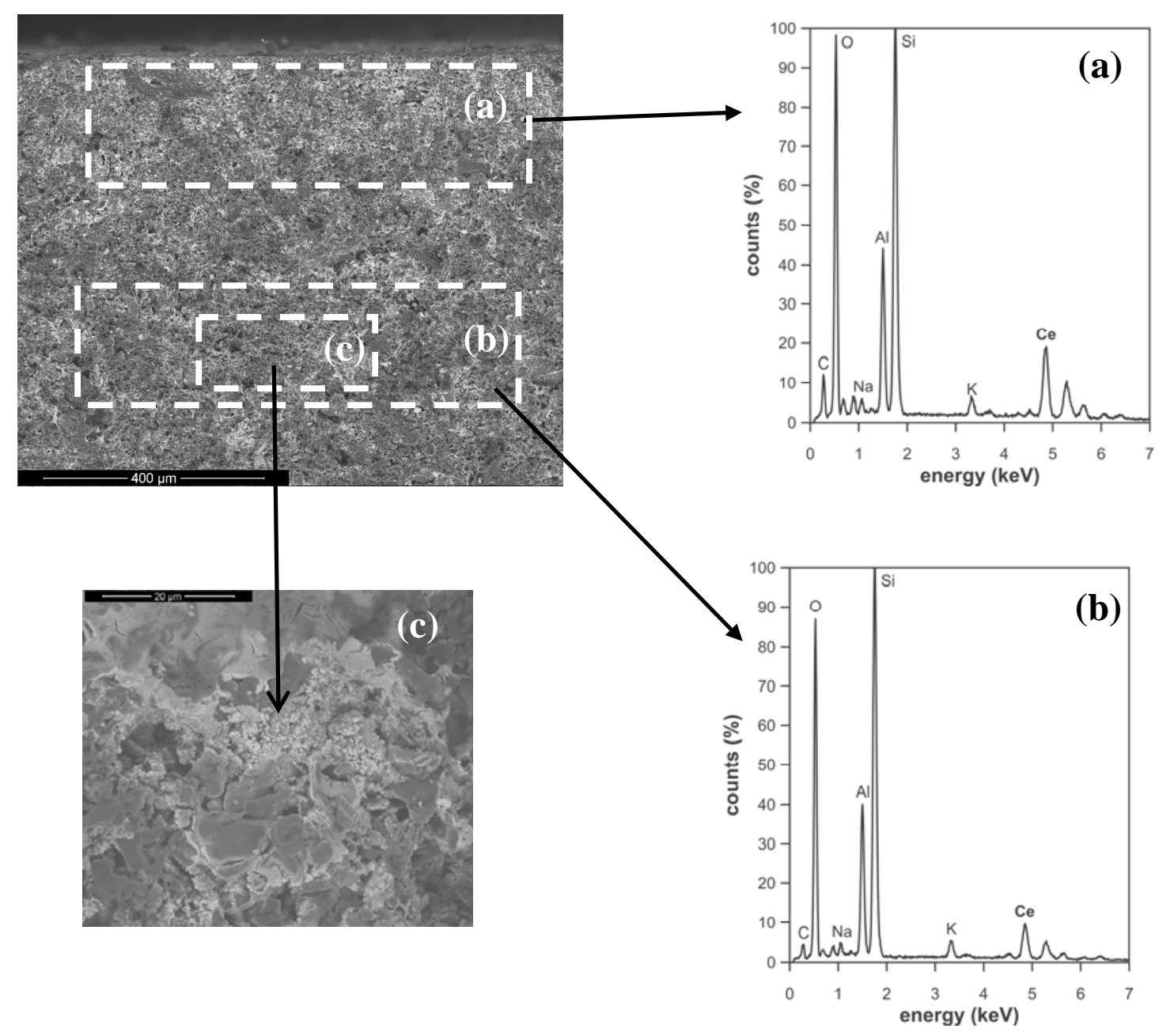

Fig 3. SEM image and EDX analysis of polished sections of the membrane obtained with 6 infiltration cycles and $250^{\circ} \mathrm{C}$ : (a) Surface of the membrane, (b) central section and (c) magnification of central section of the membrane (the whitest areas correspond to the cerium hydrated oxide). 


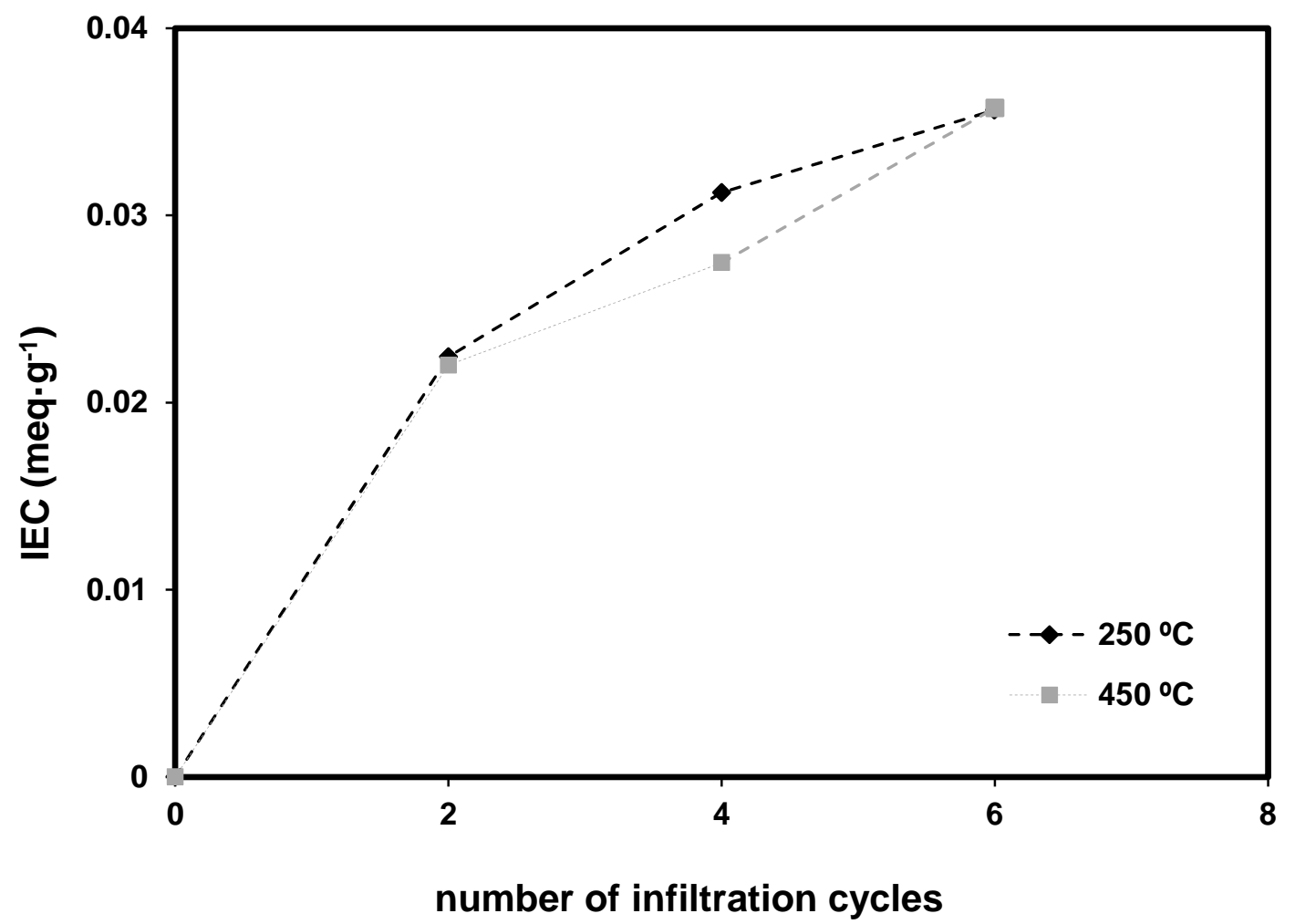

Fig. 4. Effect of the number of infiltration cycles with hydrated $\mathrm{CeO}_{2}$ (n) on IEC. 


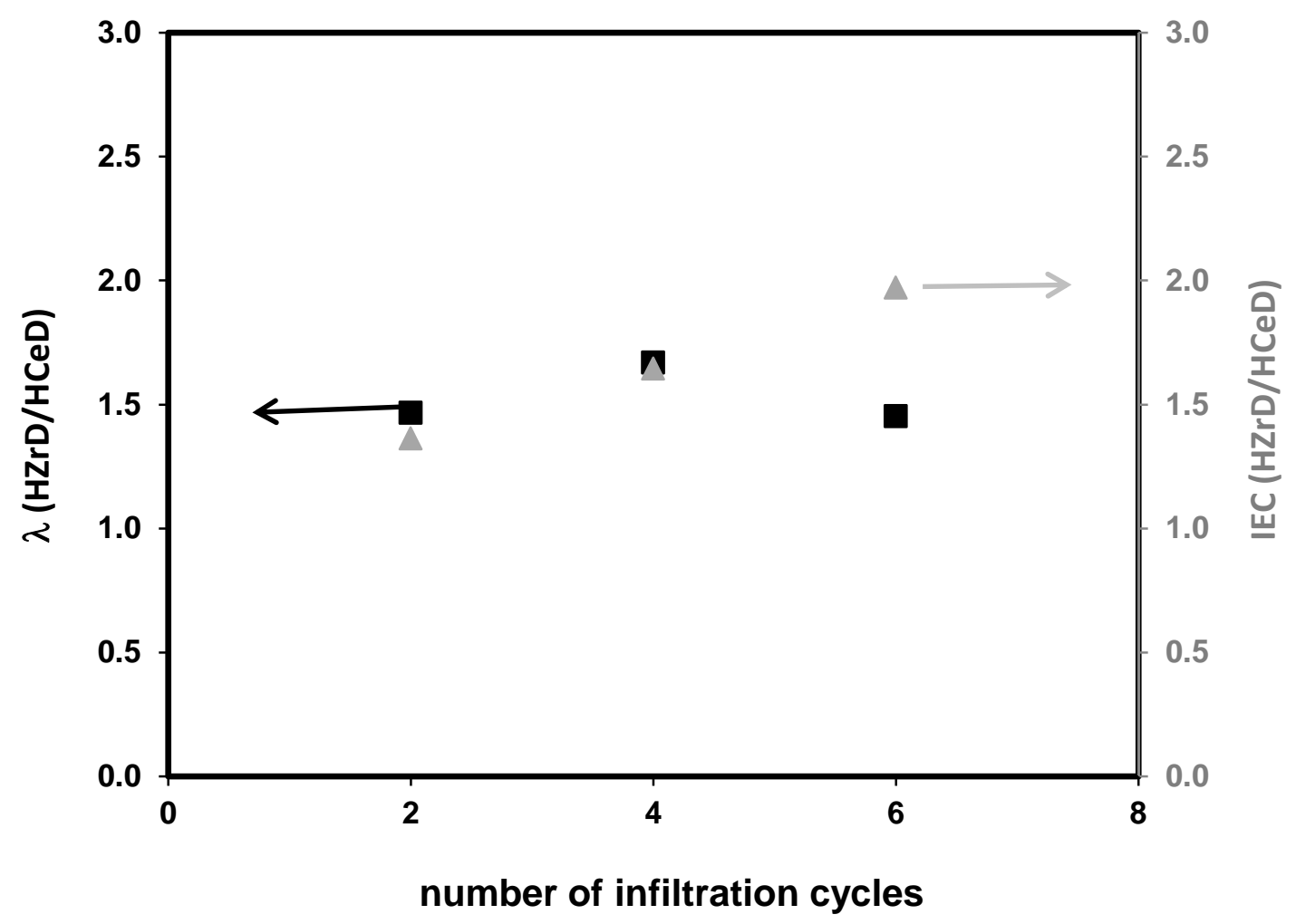

Fig. 5. Effect of the number of infiltration cycles on the ratio of $\lambda$ and IEC expressed as HZrD/ HCeD. 


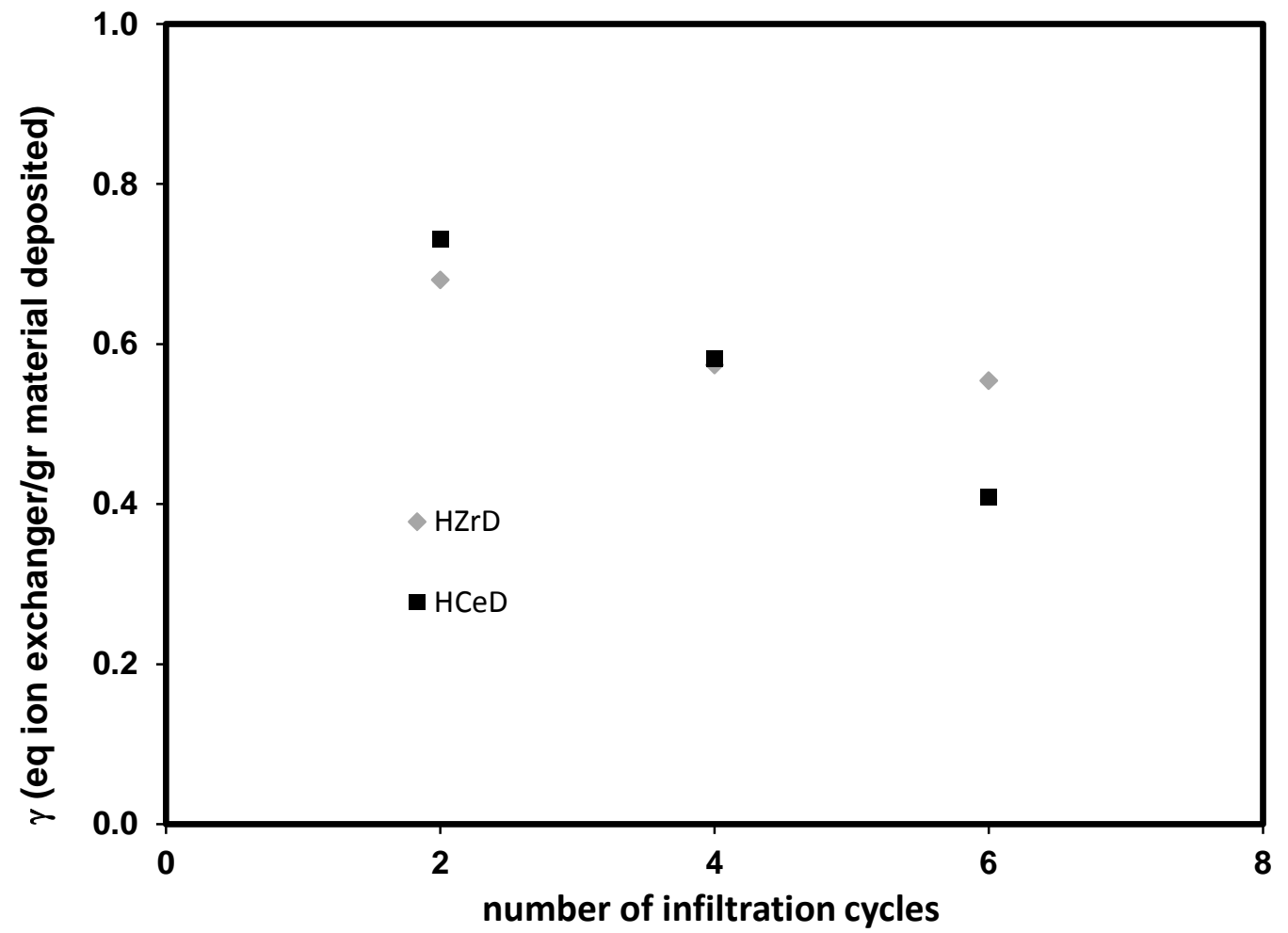

Fig. 6. Ion-exchange capacity per gram of material deposited 

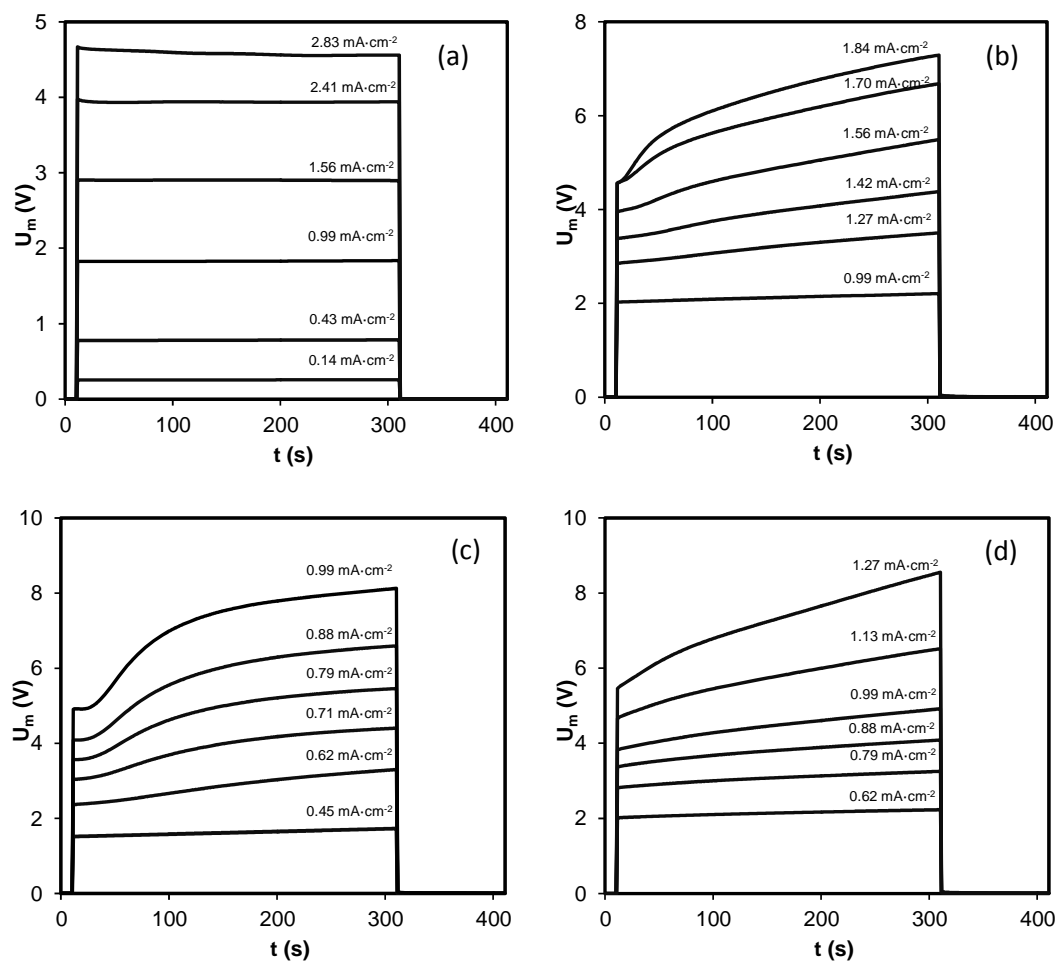

Fig. 7. Chronopotentiometric response obtained for $0.01 \mathrm{M} \mathrm{NaCl}$ with (a) the microporous support without $\mathrm{CeO}_{2}(n=0)$, and the membranes infiltrated with $\mathrm{HCeD}$ : (b) $n=2$, (c) $n=4$, and (d) $n=6$. 

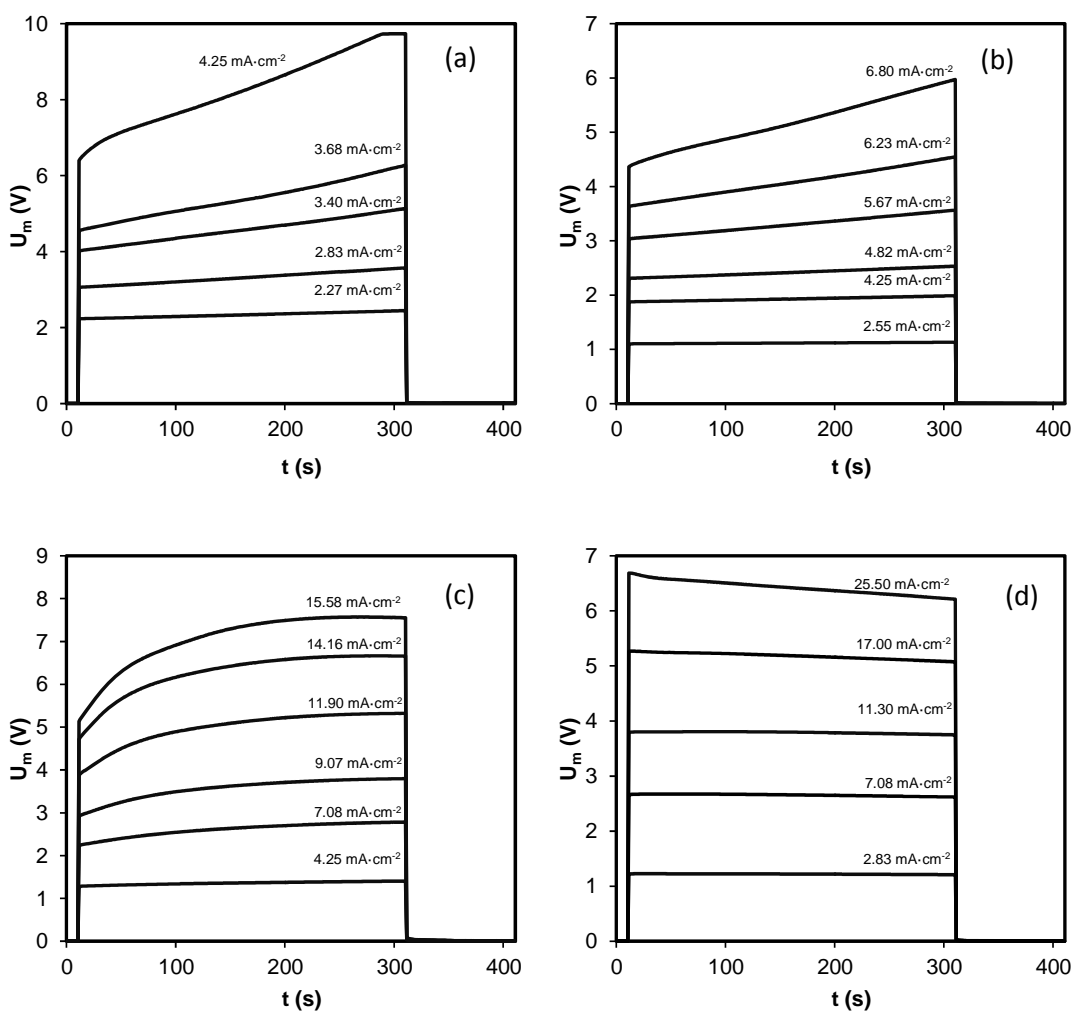

Fig. 8. Chronopotentiometric response obtained for the membrane obtained after 6 infiltration cycles with different electrolyte solutions: (a) $0.05 \mathrm{M} \mathrm{NaCl}$, (b) $0.1 \mathrm{M} \mathrm{NaCl}$, (c) $0.05 \mathrm{M} \mathrm{HCl}$ and (d) mixtures of 0.05 $\mathrm{M} \mathrm{NaCl}$ and $0.05 \mathrm{M} \mathrm{NaOH}$. 


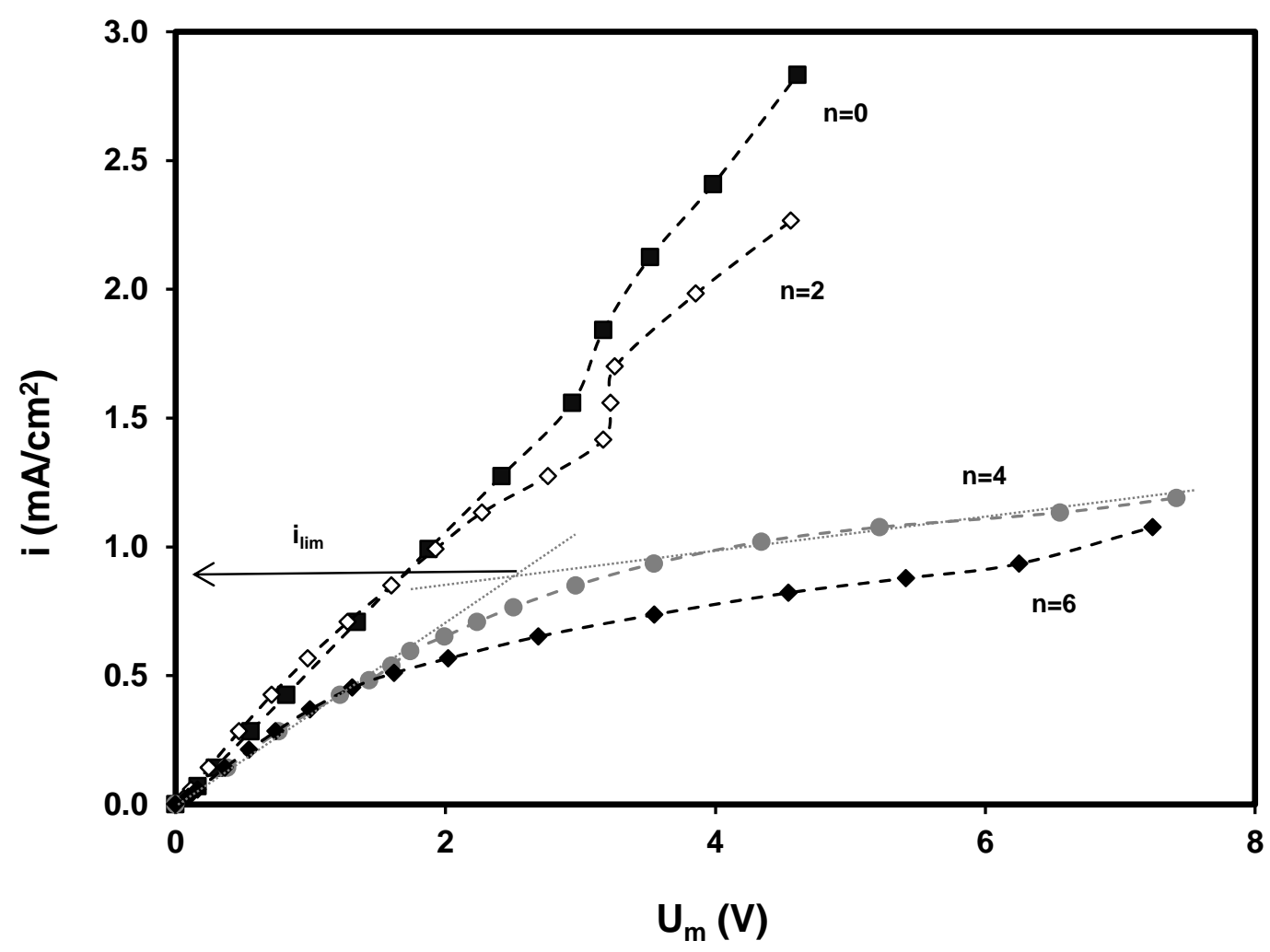

Fig. 9. Current-voltage curves obtained for $0.01 \mathrm{M} \mathrm{NaCl}$ solutions and varying number of infiltration steps. The thermal treatment applied to fix the anion-exchanger was conducted at $\mathrm{T}=450^{\circ} \mathrm{C}$ 


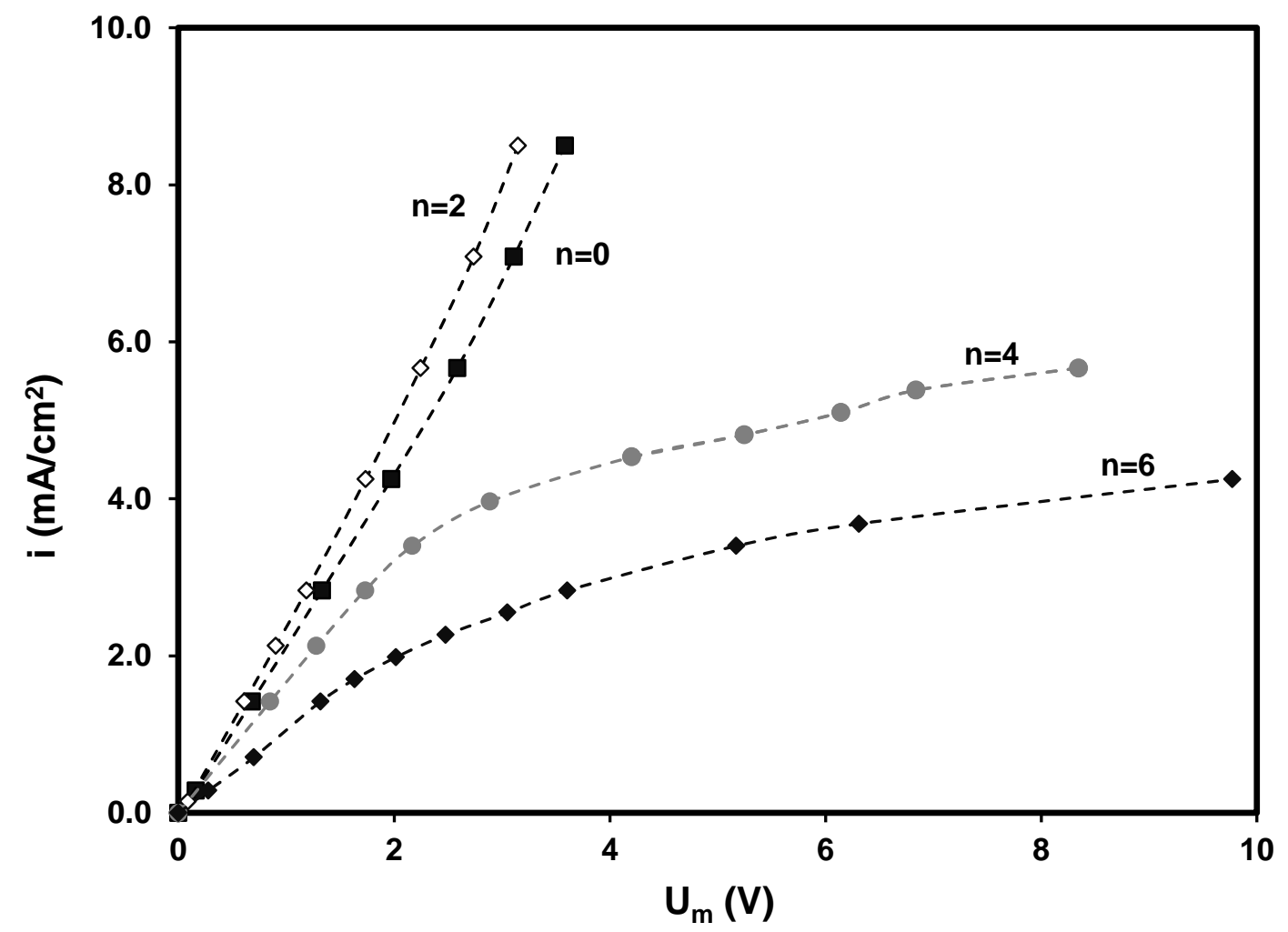

Fig. 10. Current-voltage curves obtained for $0.05 \mathrm{M} \mathrm{NaCl}$ solutions and varying number of infiltration steps. The thermal treatment applied to fix the anion-exchanger was conducted at $\mathrm{T}=250^{\circ} \mathrm{C}$ 
Table 1.

Chemical composition of inorganic raw materials (wt \%).

\begin{tabular}{cccc}
\hline Oxide & Clay & Sodium feldspar & Feldspatic sand \\
\hline $\mathrm{SiO}_{2}$ & 64.5 & 70 & 91 \\
$\mathrm{Al}_{2} \mathrm{O}_{3}$ & 22.5 & 19 & 5 \\
$\mathrm{Fe}_{2} \mathrm{O}_{3}$ & 1.1 & 0.11 & 0.12 \\
$\mathrm{CaO}$ & 0.3 & 0.5 & 0.1 \\
$\mathrm{MgO}$ & 0.5 & 0.1 & 0.01 \\
$\mathrm{Na}_{2} \mathrm{O}$ & 0.5 & 10 & 0.1 \\
$\mathrm{~K}_{2} \mathrm{O}$ & 2.25 & 0.3 & 2.5 \\
$\mathrm{TiO}_{2}$ & 1.25 & 0.2 & 0.08 \\
\hline $\mathrm{L} . \mathrm{O}^{\mathrm{(a)}}$ & 6.5 & 0.3 & 1.1 \\
\hline
\end{tabular}

(a) Loss on ignition 
Table 2

Values of IEC, open porosity, and $\lambda$ for both $\mathrm{HZrD}$ and $\mathrm{HCeO}$ as a function of the number of infiltration cycles.

\begin{tabular}{|c|c|c|c|c|c|}
\hline & & $\mathbf{n}=\mathbf{0}$ & $\mathbf{n}=\mathbf{2}$ & $\mathrm{n}=4$ & $\mathbf{n}=\mathbf{6}$ \\
\hline \multirow{3}{*}{ 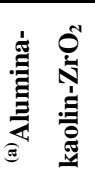 } & IEC $\left(\mathrm{meq} \cdot \mathrm{g}^{-1}\right)$ & 0 & 0.030 & 0.051 & 0.070 \\
\hline & Open porosity $(\%)$ & 53.6 & 51.8 & 50.5 & 48.5 \\
\hline & $\lambda$ (gr HZrD deposited/gr support) & 0 & 0.358 & 0.722 & 1.012 \\
\hline \multirow{3}{*}{ Ũ } & IEC $\left(\mathrm{meq} \cdot \mathrm{g}^{-1}\right)$ & 0 & 0.022 & 0.031 & 0.036 \\
\hline & Open porosity $(\%)$ & 30.8 & 30.3 & 27.9 & 29.6 \\
\hline & $\lambda$ (gr HCeD deposited/gr support) & 0 & 0.169 & 0.299 & 0.481 \\
\hline
\end{tabular}

(a) Temperature of the thermal treatment $=200^{\circ} \mathrm{C}$

(b) Temperature of the thermal treatment $=2500^{\circ} \mathrm{C}$ 
Table 3

Values of the electrochemical parameters as a function of the number of infiltration cycles and temperature.

\begin{tabular}{|c|c|c|c|c|c|c|c|c|}
\hline \multirow{2}{*}{\multicolumn{2}{|c|}{$\frac{n}{T\left({ }^{\circ} \mathbf{C}\right)}$}} & \multirow[t]{2}{*}{$\mathbf{0}$} & \multicolumn{2}{|c|}{2} & \multicolumn{2}{|c|}{4} & \multicolumn{2}{|c|}{6} \\
\hline & & & 250 & 450 & 250 & 450 & 250 & 450 \\
\hline \multirow{2}{*}{ 0.01M NaCl } & $\mathrm{k}_{\mathrm{m}}\left(\mathrm{mS} \cdot \mathrm{cm}^{-1}\right)$ & 0.17 & 0.14 & 0.16 & 0.09 & 0.11 & 0.10 & 0.12 \\
\hline & $\mathrm{i}_{\lim }\left(\mathrm{mA} \cdot \mathrm{cm}^{-2}\right)$ & - & 1.19 & 1.00 & 0.50 & 0.90 & 0.75 & 0.58 \\
\hline \multirow{2}{*}{$0.05 \mathrm{M} \mathrm{NaCl}$} & $\mathrm{k}_{\mathrm{m}}\left(\mathrm{mS} \cdot \mathrm{cm}^{-1}\right)$ & 0.75 & 0.77 & 0.67 & 0.46 & 0.51 & 0.33 & 0.32 \\
\hline & $\mathrm{i}_{\lim }\left(\mathrm{mA} \cdot \mathrm{cm}^{-2}\right)$ & - & - & - & 4.07 & 2.87 & 3.02 & 2.96 \\
\hline \multirow{2}{*}{$0.1 \mathrm{M} \mathrm{NaCl}$} & $\mathrm{k}_{\mathrm{m}}\left(\mathrm{mS} \cdot \mathrm{cm}^{-1}\right)$ & 1.41 & 1.21 & 1.36 & 0.76 & 0.79 & 0.66 & 0.60 \\
\hline & $\mathrm{i}_{\lim }\left(\mathrm{mA} \cdot \mathrm{cm}^{-2}\right)$ & - & - & - & 5.78 & - & 5.06 & 4.57 \\
\hline \multirow{2}{*}{ 0.05M HCl } & $\mathrm{k}_{\mathrm{m}}\left(\mathrm{mS} \cdot \mathrm{cm}^{-1}\right)$ & 3.07 & 1.97 & 2.54 & 1.04 & 1.49 & 0.99 & 1.15 \\
\hline & $\mathrm{i}_{\lim }\left(\mathrm{mA} \cdot \mathrm{cm}^{-2}\right)$ & - & 23.39 & - & 16.12 & 20.63 & 4.30 & 3.28 \\
\hline
\end{tabular}

